\title{
Rendimento de grãos de soja em função de sistemas de plantio e irrigação por superfície em Planossolos
}

\author{
Gerson Meneghetti Sarzi Sartori(1), Enio Marchesan ${ }^{(1)}$, Ricardo De David(1), Reimar Carlesso(1), \\ Mirta Teresinha Petry(1), Gabriel Donato(1), Alberto Cargnelutti Filho(1) e Marília Ferreira da Silva(1)
}

(1)Universidade Federal de Santa Maria, Avenida Roraima, o 1.000, Cidade Universitária, Bairro Camobi, CEP 97105-900 Santa Maria, RS, Brasil. E-mail: gersonmss@yahoo.com.br, eniomarchesan@gmail.com, ricardodd13@hotmail.com, reimar.carlesso@gmail.com, mirta. petry@gmail.com, gabriel.donato@hotmail.com, alberto.cargnelutti.filho@gmail.com, mariliaf312@yahoo.com.br

Resumo - O objetivo deste trabalho foi avaliar o efeito de sistemas de plantio e irrigação suplementar em faixas sobre o rendimento de grãos de soja, em áreas com presença de camada compactada próxima à superfície do solo. Dois experimentos foram realizados em blocos ao acaso, em faixas, com quatro repetições, no Estado do Rio Grande do Sul. O experimento 1 foi realizado em Santa Maria, correspondente às safras de 2013/2014 e 2014/2015; e o experimento 2, em Formigueiro, na safra 2013/2014. Os tratamentos consistiram dos fatores A e D. O fator A considerou os seguintes sistemas de plantio: A1, semeadura com discos duplos desencontrados; A2, semeadura com disco ondulado de 12 ondas; A3, semeadura com haste sulcadora; A4, semeadura com haste sulcadora e um mecanismo de acomodação do solo; A5, semeadura em microcamalhão; e A6, escarificação do solo e semeadura com disco duplo desencontrado. O fator D consistiu de tratamentos com ou sem irrigação. Na safra 2014/2015, alterou-se o fator A4 por haste desencontrada a $5 \mathrm{~cm}$ da linha de semeadura. O experimento 2 constituiu-se apenas do fator A do experimento 1, sem o tratamento microcamalhão. Os sistemas com escarificação do solo e haste sulcadora são os que proporcionam maior rendimento de grãos. A irrigação realizada em condições de umidade do solo abaixo de $60 \%$ da capacidade de campo aumenta o rendimento de grãos.

Termos para indexação: Glycine max, áreas de várzea, camada compactada do solo, mecanismos da semeadora, nodulação.

\section{Soybean yield under different planting systems and border irrigation on Alfisols}

Abstract - The objective of this work was to evaluate the effect of planting systems and supplementary border irrigation on soybean yield in areas of a compacted layer in the soil subsurface. Two experiments were carried out in a randomized complete block design, in a factorial arrangement, with four replicates, in the state of Rio Grande do Sul, Brazil. Experiment 1 was performed in Santa Maria, in the 2013/2014 and 2014/2015 growing seasons; and experiment 2 in Formigueiro, in the 2013/2014 crop season. The treatments consisted of factors A and D. Factor A considered the following planting systems: A1, sowing using double disks; A2, sowing using notched disks; A3, sowing using shanks; A4, sowing using shanks and soil accommodation mechanism; A5, raised bed system; and A6, deep tillage and sowing using double disks. Factor D consisted of irrigated or nonirrigated treatments. In the 2014/2015 growing season, factor A4 was changed using a shank at $5 \mathrm{~cm}$ from the seeding line. Experiment 2 consisted only of factor A of experiment 1, without the raised bed system. The systems with deep tillage and sowing using a shank provide higher soybean grain yield. Irrigation at soil moisture conditions lower than $60 \%$ of field capacity increases soybean grain yield.

Index terms: Glycine max, lowland areas, soil compaction, planter mechanism, nodulation.

\section{Introdução}

A cultura da soja é uma importante alternativa para a rotação de culturas em áreas de várzeas cultivadas com arroz irrigado, pois contribui para a interrupção de ciclos de doenças e insetos-praga e melhora as condições físicas e químicas do solo (Thomas et al., 2000). Para a soja, utilizam-se herbicidas com mecanismos de ação diferentes daqueles utilizados no arroz, o que contribui para o controle de plantas daninhas de difícil controle no arroz, especialmente o arroz-vermelho (Missio et al., 2010).

A maioria das áreas utilizadas para o cultivo do arroz irrigado pertence à classe Planossolos (Bamberg et al., 2009). Esses solos são mal drenados, com horizonte superficial ou subsuperficial eluvial, de textura mais 
leve, e contrastam abruptamente com o horizonte $\mathrm{B}$, ou apresentam transição abrupta conjugada com acentuada diferença de textura do horizonte A para o B, são adensados, geralmente com elevada concentração de argila, e de permeabilidade lenta ou muito lenta. Em áreas de várzeas, em condições de clima úmido, são considerados hidromórficos, com horizonte plânico e apresentam características de horizonte glei (Santos et al., 2013). Além disso, em consequência das práticas de preparo do solo para o cultivo do arroz irrigado, parte dessas áreas apresenta camada compactada, em média entre 7 e $17 \mathrm{~cm}$ de profundidade, que influencia a quantidade de macroporos (Valicheski et al., 2012), a porosidade total (Drescher et al., 2011) e as relações solo-ar-água. Em razão das características intrínsecas dessa classe de solos associada à presença de uma camada compactada, ocorrem estresses nas plantas de soja em anos de excesso e de deficit hídrico, com efeitos negativos sobre o crescimento das plantas e a fixação biológica de nitrogênio (Abreu et al., 2004), o que pode interferir no rendimento de grãos da cultura. Assim, é fundamental identificar alternativas para a minimização desses estresses, pois o êxito de culturas como a soja depende da adequação do ambiente de várzea às suas exigências agronômicas (Vernetti Junior et al., 2009). Em anos de excesso de chuvas, é necessário reduzir o tempo de estresse da planta por falta de oxigênio, especialmente na região de maior volume de raízes e nódulos, o que pode ser feito por meio de implementos agrícolas, para que as plantas possam apresentar melhor desempenho agronômico. A escarificação do solo, ou o uso de diferentes mecanismos da semeadora, durante a operação de semeadura, a exemplo da haste sulcadora, tem apresentado efeitos positivos na descompactação do solo na linha de cultivo (Drescher et al., 2011). O sistema de implantação em microcamalhão, em que a água da irrigação é derivada para o sulco entre dois microcamalhões, é muito utilizado nos Estados Unidos, Ásia, Austrália e México, pois permite o cultivo de soja, milho, sorgo, algodão e trigo em áreas excessivamente úmidas e frias, com economia de água e excelentes rendimentos. Entretanto, no Brasil, essa prática é pouco utilizada pelos agricultores, pois não há informação suficiente sobre esse sistema, assim como sobre o uso de mecanismos da semeadora como disco duplo, disco ondulado e haste sulcadora, para implantação de culturas como a soja em área de várzea.
Informações sobre o uso da irrigação em faixas ou canteiros no cultivo da soja em várzea são escassas, em razão da ausência de pesquisas específicas sobre a rotação de culturas e sistemas de plantio em várzeas, com exceção do arroz. Consequentemente, estudos sobre o efeito da irrigação em soja, nessas áreas, são fundamentais, pois o estresse hídrico pode causar redução do potencial hídrico foliar, fechamento estomático, diminuição da taxa fotossintética, redução da parte aérea, aceleração da senescência e abscisão das folhas (Ferrari et al., 2015), uma vez que a água é um dos principais fatores que afeta o rendimento de grãos de soja (Fernandes \& Turco, 2003). De acordo com Zhang et al. (2015), a irrigação contribui para diminuir os impactos climáticos negativos, especificamente seca e calor extremos sobre a cultura da soja, e pode também minimizar parte dos efeitos causados pela camada compactada do solo (Kirnak et al., 2013).

O objetivo deste trabalho foi avaliar sistemas de plantio e irrigação suplementar em faixas irrigadas, no rendimento de grãos de soja, em áreas com camada compactada próxima à superfície do solo.

\section{Material e Métodos}

Dois experimentos foram realizados: o experimento 1, nas safras de 2013/2014 e 2014/2015, em Santa Maria, RS; e o experimento 2, na safra de 2013/2014, em Formigueiro, RS.

$\mathrm{O}$ experimento 1 foi realizado em área de várzea sistematizada, pertencente à Universidade Federal de Santa Maria, em locais diferentes da área experimental nos dois anos. O solo em que foi realizado o experimento é classificado como Planossolo Háplico eutrófico arênico, pertencente à unidade de mapeamento Vacacaí (Santos et al., 2013). Na safra 2013/2014, este solo apresentava na camada de $0-20,0 \mathrm{~cm}$, aos 60 dias antes da semeadura, os seguintes atributos físico-químicos: argila, $250 \mathrm{~g} \mathrm{~kg}^{-1} ; \mathrm{pH}_{\text {água }}(1: 1), 5,4 ; \mathrm{P}, 18 \mathrm{mg} \mathrm{dm}^{-3} ; \mathrm{K}$, $60 \mathrm{mg} \mathrm{dm}{ }^{-3}$; Ca, 5,3 $\mathrm{cmol}_{\mathrm{c}} \mathrm{dm}^{-3} ; \mathrm{Mg}, 2,4 \mathrm{cmol}_{\mathrm{c}} \mathrm{dm}^{-3}$; e MO, 20,0 $\mathrm{g} \mathrm{kg}^{-1}$. E, na safra de 2014/2015, este solo apresentava a seguinte composição: argila, $260 \mathrm{~g} \mathrm{~kg}^{-1} ; \mathrm{pH}_{\text {água }}(1: 1), 5,4 ; \mathrm{P}, 15,3 \mathrm{mg} \mathrm{dm}^{-3} ; \mathrm{K}$, $44 \mathrm{mg} \mathrm{dm}{ }^{-3}$; Ca, 8,3 $\mathrm{cmol}_{\mathrm{c}} \mathrm{dm}^{-3} ; \mathrm{Mg}, 3,1 \mathrm{cmol}_{\mathrm{c}} \mathrm{dm}^{-3}$, e $\mathrm{MO}, 20,0 \mathrm{~g} \mathrm{~kg}^{-1}$. Nesta mesma época, na camada de 0,0-20 cm, o solo apresentava os valores médios na safra de 2013/2014: de densidade, 1,50 $\mathrm{Mg} \mathrm{m}^{-3}$; porosidade total, $0,48 \mathrm{~m}^{3} \mathrm{~m}^{-3}$; microporosidade, 
$0,36 \mathrm{~m}^{3} \mathrm{~m}^{-3}$; e macroporosidade, $0,10 \mathrm{~m}^{3} \mathrm{~m}^{-3}$. Para a mesma camada, na safra $2014 / 2015$, os seguintes valores médios foram encontrados: densidade, 1,53 $\mathrm{Mg} \mathrm{m} \mathrm{m}^{-3}$; porosidade total, $0,40 \mathrm{~m}^{3} \mathrm{~m}^{-3}$; microporosidade, $0,32 \mathrm{~m}^{3} \mathrm{~m}^{-3}$; e macroporosidade, $0,09 \mathrm{~m}^{3} \mathrm{~m}^{-3}$.

Aos dez dias antes da semeadura, com um penetrômetro digital Falker PLG1020 (Falker, Porto Alegre, RS, Brasil), o solo continha os seguintes valores de resistência à penetração: $0,2,1,6,2,1,2,1$, 1,9 e 1,7 MPa (safra 2013/2014) e 0,2, 3,0, 2,3, 2,1, 1,0, 0,6 MPa (safra 2014/2015), nas camadas do solo de $0-5,5-10,10-15,15-20,20-25$ e $25-30 \mathrm{~cm}$ de profundidade, respectivamente. A umidade volumétrica do solo, por ocasião da avaliação, era de 26 e $20 \%$, para as safras 2013/2014 e 2014/2015, respectivamente.

Para o experimento, utilizou-se o delineamento experimental de blocos ao acaso, em arranjo fatorial $6 \times 2$, em faixas, com quatro repetições. Os tratamentos consistiram de fator A e fator D. O fator A abrangeu os seguintes sistemas de implantação: A1, semeadura com disco duplo desencontrado; A2, semeadura com disco ondulado de 12 ondas; A3, semeadura com haste sulcadora; A4, semeadura com haste sulcadora e mecanismo de acomodação do solo; A5, semeadura em microcamalhão; e A6, escarificação do solo e semeadura com disco duplo desencontrado. $\mathrm{O}$ fator D abrangeu os tratamentos com ou sem irrigação. $\mathrm{Na}$ safra 2014/2015, trocou-se o fator A4 por haste desencontrada a $5 \mathrm{~cm}$ da linha de semeadura.

$\mathrm{O}$ experimento 2 foi realizado em área com relevo suave-ondulado, e o solo foi classificado como Planossolo Háplico eutrófico típico, pertencente à unidade de mapeamento São Gabriel (Santos et al., 2013), com os seguintes atributos físico-químicos, aos 50 dias antes da semeadura, na camada de 0,0-20 cm: argila, $340 \mathrm{~g} \mathrm{~kg}^{-1} ; \mathrm{pH}_{\text {água }}(1: 1), 5,2 ; \mathrm{P}$, 2,2 $\mathrm{mg} \mathrm{dm}^{-3}$; K, $112 \mathrm{mg} \mathrm{dm}^{-3}$; Ca, 10,5 $\mathrm{cmol}_{\mathrm{c}} \mathrm{dm}^{-3}$; $\mathrm{Mg}, 8,0 \mathrm{cmol}_{\mathrm{c}} \mathrm{dm}^{-3}$; e $\mathrm{MO}, 16 \mathrm{~g} \mathrm{~kg}^{-1}$. Aos dez dias antes da semeadura, na camada de 0,0-20 cm, o solo apresentava os seguintes valores: densidade, 1,60 Mg m $\mathrm{m}^{-3}$; porosidade total, $0,36 \mathrm{~m}^{3} \mathrm{~m}^{-3}$; microporosidade, $0,35 \mathrm{~m}^{3} \mathrm{~m}^{-3}$; e macroporosidade, $0,03 \mathrm{~m}^{3} \mathrm{~m}^{-3}$. O solo do experimento 2 apresentava, ainda, os seguintes valores de resistência à penetração: $0,3,3,0,1,8,1,4,1,2$ e 1,3 $\mathrm{MPa}$, nas camadas do solo de $0-5,5-10,10-15,15-20,20-25$ e $25-30 \mathrm{~cm}$ de profundidade, respectivamente. Por ocasião da avaliação de resistência à penetração, o solo apresentava $25,5 \%$ de umidade volumétrica média.

Para o experimento 2, utilizou-se um delineamento de blocos completos ao acaso, com quatro repetições. Os tratamentos foram os mesmos do experimento 1, para a safra 2013/2014, porém, sem o tratamento microcamalhão e irrigação.

A escarificação do solo no experimento 1 , na safra de 2013/2014, foi realizada aos 45 dias antes da semeadura e, na safra de 2014/2015, aos 19 dias antes da semeadura. No experimento 2, a escarificação do solo foi realizada por ocasião da semeadura. A profundidade da escarificação do solo foi de $25 \mathrm{~cm}$, e o espaçamento entre as hastes do escarificador, de $35 \mathrm{~cm}$. As profundidades de trabalho da haste sulcadora, da haste sulcadora no sistema em microcamalhão, do disco duplo e do disco ondulado no solo foram aproximadamente de $18,12,10$ e $8 \mathrm{~cm}$, respectivamente.

A semeadura do experimento 1 foi realizada nos dias 7 e 14 de novembro de 2013 e 2014, respectivamente, com uma semeadora-adubadora pantográfica. Em decorrência de uma precipitação pluvial de $245 \mathrm{~mm}$ aos dois dias após a semeadura, na safra 2013/2014, realizou-se a ressemeadura do experimento no dia 26 de novembro de 2013. A semeadura do experimento 2 foi realizada no dia 5 de novembro de 2013. A cultivar de soja utilizada para ambos os experimentos foi a 'BMX Tornado RR (6863 RSF)', com 26 sementes $\mathrm{m}^{-2}$, com $0,5 \mathrm{~m}$ de distância entre linhas.

As sementes foram tratadas com fipronil $\left(250 \mathrm{~g} \mathrm{~L}^{-1}\right)$ e carbendazim + thiram $\left(150 \mathrm{~g} \mathrm{~L}^{-1}+350 \mathrm{~g} \mathrm{~L}^{-1}\right)$, à dose de $150 \mathrm{~mL}$ e $200 \mathrm{~mL} 100 \mathrm{~kg}^{-1}$ de semente, respectivamente, e foram inoculadas com estirpes de Bradyrhizobium japonicum (100g 50 $\mathrm{kg}^{-1}$ de semente). A adubação de base na safra de 2013/2014, para os experimentos 1 e 2 , foi de $30 \mathrm{~kg} \mathrm{ha}^{-1}$ de $\mathrm{N}, 60 \mathrm{~kg} \mathrm{ha}^{-1}$ de $\mathrm{P}_{2} \mathrm{O}_{5}$ e $60 \mathrm{~kg} \mathrm{ha}^{-1}$ de $\mathrm{K}_{2} \mathrm{O}$. No entanto, para o experimento 1 , em razão da ressemeadura, utilizou-se mais $10 \mathrm{~kg} \mathrm{ha}^{-1}$ de N, $20 \mathrm{~kg} \mathrm{ha}^{-1} \mathrm{de}_{2} \mathrm{O}_{5}$ e $20 \mathrm{~kg} \mathrm{ha}^{-1} \mathrm{de}$ $\mathrm{K}_{2} \mathrm{O}$. Na safra de 2014/2015, a adubação de base foi de $13 \mathrm{~kg} \mathrm{ha}^{-1}$ de N, $55 \mathrm{~kg} \mathrm{ha}^{-1}$ de $\mathrm{P}_{2} \mathrm{O}_{5}$ e $87 \mathrm{~kg} \mathrm{ha}^{-1}$ de $\mathrm{K}_{2} \mathrm{O}$. Os demais tratos culturais foram realizados conforme as recomendações técnicas para cultura (Costamilan et al., 2012).

A irrigação com vazão média de $5 \mathrm{~L} \mathrm{~s}^{-1}$ foi aplicada por superfície, em faixas irrigadas. No experimento 1, realizou-se uma irrigação na safra de 2013/2014, com 
lâmina de irrigação de $55 \mathrm{~mm}$, quando a umidade média do solo se encontrava em $58 \%$ da capacidade de campo (CC) à profundidade de $0-20 \mathrm{~cm}$, no estádio V4 das plantas, e duas irrigações na safra de 2014/2015, das quais uma de $41 \mathrm{~mm}$ no estádio R3, e outra de $46 \mathrm{~mm}$ em R5, segundo escala de Fehr \& Caviness (1977). A umidade do solo na camada de 0-20 cm, em R3 e R5, encontrava-se em 60,6 e 54,2\% da $\mathrm{CC}$, respectivamente. As unidades experimentais mediram $40 \times 3 \mathrm{~m}$ e $60 \times 3 \mathrm{~m}$ para os experimentos 1 e 2 , respectivamente, com área útil de $15 \mathrm{~m}^{2}$ cada.

Avaliou-se o conteúdo de oxigênio do solo à profundidade de $0-10 \mathrm{~cm}$, durante todo o ciclo da cultura, por meio do medidor de oxigênio ICT-SOM (ICT International, Armidale, New South Wales, Austrália), com sensores de oxigênio modelo ICT- $\mathrm{O}_{2}$ colocados na linha de semeadura. Avaliaram-se, ainda, a densidade (Ds), porosidade total (PT), microporosidade (Mi) e macroporosidade (Ma) do solo, no estádio V6 das plantas. Para essa avaliação, coletaram-se amostras de solo das camadas de 0-10 e de $10-20 \mathrm{~cm}$, na linha de semeadura da cultura, por meio de anéis volumétricos de 4,0 e $4,8 \mathrm{~cm}$ de altura e diâmetro, respectivamente. Após as coletas, as amostras de solo foram encaminhadas para laboratório e analisadas segundo as técnicas descritas por Donagema et al. (2011). A Ds foi determinada pelo método volumétrico, a PT foi assumida como a umidade de saturação, a Mi pelo método da mesa de tensão a 0,6 m, e a Ma pela diferença entre PT e Mi.

Realizou-se a média das duas camadas de solo, tendo-se obtido os resultados referentes a camada de 0-20 cm. As variáveis avaliadas nas plantas foram: estatura de plantas, área foliar, massa de matéria seca da parte aérea, número e massa de matéria seca de nódulos e rendimento de grãos. As cinco primeiras avaliações foram realizadas nos estádios V6 e R3, para ambos os experimentos, com exceção do índice de área foliar, que foi avaliado apenas no V6, e da nodulação das plantas que, no experimento 2, foi avaliada em R3.

Para avaliar a estatura das plantas, a área foliar, e a massa de matéria seca da parte aérea, coletou-se a parte aérea de cinco plantas em sequência, na linha de cultivo rente ao solo que, posteriormente, foram acondicionadas em embalagens de plástico e encaminhadas ao laboratório. Determinou-se a estatura das cinco plantas, com régua graduada, a área foliar em três plantas, por meio de medidor portátil
LI-3000C (LI-COR, Lincoln, NE, EUA) e, em seguida, calculou-se o IAF conforme Radin et al. (2003). Após essas avaliações, a parte aérea das cinco plantas foi seca em estufa de circulação forçada de ar à temperatura de $65^{\circ} \mathrm{C}$ até a obtenção de massa constante.

Para a determinação da nodulação, coletou-se um

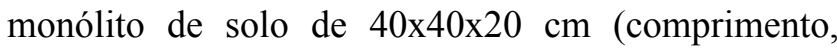
largura e profundidade), com as raízes das cinco plantas, para avaliar o número de nódulos por planta, a viabilidade de nódulos e a massa de matéria seca dos nódulos, segundo metodologia de Vieira Neto et al. (2008). O rendimento de grãos foi avaliado ao final do ciclo (R8), a partir da parcela útil de $10 \mathrm{~m}^{2}$.

Os valores de precipitação pluvial para o experimento 1 foram obtidos da EstaçãoMeteorológicaAutomática do $8^{\circ}$ Disme/Inmet, localizada no Departamento de Fitotecnia da UFSM, a aproximadamente $500 \mathrm{~m}$ do experimento. Para o experimento 2, os dados de precipitação pluvial foram obtidos por pluviômetro AcuRite (AcuRite, Lake Geneva, WI, EUA), instalado a $200 \mathrm{~m}$ do experimento. Os resultados foram submetidos ao teste das pressuposições, do modelo matemático de normalidade e homogeneidade das variâncias. A análise da variância dos dados dos experimentos foi realizada pelo teste $\mathrm{F}$. As médias dos fatores, quando significativas, foram comparadas pelo teste de Tukey, a $5 \%$ de probabilidade.

\section{Resultados e Discussão}

A área em que foi realizado o experimento 1 apresentava resistência à penetração de $2,1 \mathrm{MPa}$ na camada de 10-20 cm, na safra de 2013/2014, e de 3,0 MPa na camada de 5-20 cm, na safra de 2014/2015. Os sistemas de implantação influenciaram a qualidade física do solo no experimento 1 (Tabela 1). Os sistemas que utilizaram haste sulcadora na semeadora, o sistema em microcamalhão e a escarificação reduziram a densidade média do solo, na camada de 0-20 cm, e aumentaram a porosidade total e a macroporosidade do solo nessa mesma camada, na linha de semeadura, em comparação ao disco duplo e ondulado nas safras de $2013 / 2014$ e 2014/2015. Os discos duplo e ondulado não foram eficientes em reduzir a camada compactada na linha de semeadura, o que está de acordo com os resultados obtidos por Drescher et al. (2011), em que o disco apresenta menor resposta de rompimento da camada compactada, fato associado ao menor efeito 
em profundidade no solo. De acordo com Nunes et al. (2014), o emprego da haste sulcadora proporciona aumento da macroporosidade, da porosidade total e redução da densidade do solo e resistência à penetração da camada compactada na linha de cultivo.

Observou-se que os sistemas de implantação influenciaram a qualidade física do solo, com resposta no crescimento das plantas (estatura e massa de matéria seca da parte aérea). Em geral, o sistema com escarificação do solo, seguido dos sistemas com haste sulcadora e microcamalhão resultaram em maior estatura de plantas e massa de matéria seca da parte aérea, nos estádios V6 e R3, nas safras de 2013/2014 e de 2014/2015. Para o índice de área foliar (IAF), a maior resposta observada no sistema com escarificação do solo, que proporcionou maior IAF. Além disso, houve maior número e matéria seca de nódulos no estádio V6 no sistema com escarificação do solo, na safra 2013/2014 (Tabela 2). Resultado semelhante ocorreu para a safra 2014/2015, em que houve maior número e massa de matéria seca de nódulos em V6 e R3, para esse sistema, seguido dos sistemas com haste sulcadora e em microcamalhão. A menor nodulação foi verificada no sistema de semeadura que utilizou disco duplo (safra 2013/2014) e no que utilizou disco duplo e disco ondulado (safra 2014/2015). Além disso, no sistema com disco duplo, houve maior inviabilização

Tabela 1. Densidade do solo (Ds), porosidade total (PT), microporos (Mi), macroporos (Ma), estatura de planta (E) e massa de matéria seca da parte aérea (MSPA), nos estádios V6 e R3 de desenvolvimento das plantas, e índice de área foliar (IAF) no estádio V6, em consequência dos sistemas de corte da semadora e irrigação para a cultivar de soja 'BMX Tornado', Santa Maria, RS, safras 2013/2014 e 2014/2015, e Formigueiro, RS, safra 2013/2014 ${ }^{(1)}$.

\begin{tabular}{|c|c|c|c|c|c|c|c|c|c|}
\hline \multirow{2}{*}{$\begin{array}{l}\text { Sistemas de } \\
\text { plantio }\end{array}$} & \multirow{2}{*}{$\begin{array}{c}\text { Ds } \\
\left(\mathrm{g} \mathrm{cm}^{-3}\right)\end{array}$} & PT no V6 & Mi no V6 & Ma no V6 & E no V6 & E no R3 & MSPA no V6 & MSPA no R3 & \multirow[t]{2}{*}{ IAF no V6 } \\
\hline & & \multicolumn{3}{|c|}{---------------( $\left(\mathrm{cm}^{3} \mathrm{~cm}^{-3}\right)$----------------- } & \multicolumn{4}{|c|}{--------------(cm)----------- $\quad$--------(g por planta)-------- } & \\
\hline & \multicolumn{9}{|c|}{ Experimento 1 em Santa Maria, safra 2013/2014 } \\
\hline Disco duplo (DD) & 1,5 & 0,45 & 0,35 & 0,11 & $22,9 c^{*}$ & $52,3 \mathrm{ab}$ & $4,9 \mathrm{bc}$ & $19,7 \mathrm{ab}$ & $2,2 b$ \\
\hline Disco ondulado & 1,5 & 0,46 & 0,34 & 0,12 & $23,7 \mathrm{bc}$ & $52,8 \mathrm{ab}$ & $4,5 \mathrm{c}$ & $19,4 \mathrm{ab}$ & $2,2 b$ \\
\hline Haste & 1,4 & 0,50 & 0,34 & 0,16 & $26,7 \mathrm{ab}$ & $51,4 \mathrm{ab}$ & $5,8 \mathrm{~b}$ & $20,5 \mathrm{ab}$ & $3,0 \mathrm{ab}$ \\
\hline Haste + MAS & 1,4 & 0,49 & 0,34 & 0,17 & $26,0 \mathrm{abc}$ & $51 \mathrm{~b}$ & $5,4 \mathrm{bc}$ & $17,8 \mathrm{~b}$ & $2,6 b$ \\
\hline Microcamalhão & 1,4 & 0,50 & 0,33 & 0,17 & $26,4 \mathrm{ab}$ & $50,4 \mathrm{~b}$ & $5,7 \mathrm{bc}$ & $19,7 \mathrm{ab}$ & $2,4 \mathrm{~b}$ \\
\hline Escarificado + DD & 1,4 & 0,49 & 0,33 & 0,17 & $28,1 \mathrm{a}$ & $56,8 \mathrm{a}$ & $7,1 \mathrm{a}$ & $23,1 \mathrm{a}$ & $3,9 \mathrm{a}$ \\
\hline \multicolumn{10}{|l|}{ Irrigação } \\
\hline Com irrigação & - & - & - & - & $28,2 \mathrm{a}$ & $54,8 \mathrm{a}$ & $6,4 \mathrm{a}$ & $19,9^{\text {ns }}$ & $3,1^{\mathrm{ns}}$ \\
\hline Sem irrigação & - & - & - & - & $23,0 \mathrm{~b}$ & $50,0 \mathrm{~b}$ & $4,7 \mathrm{~b}$ & 20,1 & 2,4 \\
\hline Média & - & - & - & - & 25,6 & 52,4 & 5,55 & 20 & 2,7 \\
\hline \multirow[t]{2}{*}{ CV (\%) } & - & - & - & - & 7,1 & 4,4 & 13,0 & 14,0 & 13,7 \\
\hline & \multicolumn{9}{|c|}{ Experimento 2 em Formigueiro, safra 2013/2014 } \\
\hline Disco duplo (DD) & 1,5 & 0,43 & 0,35 & 0,08 & $16 \mathrm{~ns}$ & $40 b^{*}$ & $3,2 \mathrm{ab}$ & $14 \mathrm{ab}$ & $2,4 \mathrm{ab}$ \\
\hline Disco ondulado & 1,5 & 0,41 & 0,37 & 0,06 & 16,2 & $37,7 \mathrm{~b}$ & $2,6 \mathrm{~b}$ & $11,8 \mathrm{~b}$ & $1,7 \mathrm{~b}$ \\
\hline Haste & 1,3 & 0,50 & 0,34 & 0,16 & 15,7 & $44,7 \mathrm{ab}$ & $3,5 \mathrm{ab}$ & $19,0 \mathrm{a}$ & $2,4 \mathrm{ab}$ \\
\hline Haste + MAS & 1,3 & 0,49 & 0,34 & 0,16 & 16,6 & $43,7 \mathrm{ab}$ & $4,1 \mathrm{ab}$ & $16,1 \mathrm{ab}$ & $2,8 \mathrm{ab}$ \\
\hline Escarificado + DD & 1,3 & 0,48 & 0,35 & 0,16 & 19,1 & $49,2 \mathrm{a}$ & $5,7 \mathrm{a}$ & $15,4 \mathrm{ab}$ & $3,8 \mathrm{a}$ \\
\hline Média & - & - & - & - & 16,7 & 43,1 & 3,3 & 15,3 & 2,6 \\
\hline \multirow[t]{2}{*}{ CV $(\%)$} & - & - & - & - & 10,4 & 7,3 & 29,6 & 16,3 & 17,4 \\
\hline & \multicolumn{9}{|c|}{ Experimento 1 em Santa Maria, safra 2014/2015 } \\
\hline Disco duplo (DD) & 1,6 & 0,37 & 0,32 & 0,06 & $12,2 \mathrm{~cd} *$ & $38,7 \mathrm{c}$ & $2,7 \mathrm{ab}$ & $12,4 \mathrm{bc}$ & $0,4 \mathrm{~b}$ \\
\hline Disco ondulado & 1,4 & 0,44 & 0,31 & 0,12 & $11,9 d$ & $37,9 \mathrm{c}$ & $2,5 \mathrm{~b}$ & $9,9 \mathrm{c}$ & $0,4 \mathrm{~b}$ \\
\hline Haste & 1,3 & 0,50 & 0,31 & 0,17 & $14,1 \mathrm{bc}$ & $42,2 \mathrm{bc}$ & $3,0 \mathrm{ab}$ & $11,7 b c$ & $0,5 b$ \\
\hline Haste desencontrada ${ }^{(2)}$ & 1,4 & 0,45 & 0,32 & 0,13 & $14,8 \mathrm{ab}$ & $46,5 b$ & $3,1 \mathrm{ab}$ & $15,1 \mathrm{~b}$ & $0,5 b$ \\
\hline Microcamalhão & 1,4 & 0,44 & 0,31 & 0,13 & $14,1 \mathrm{bc}$ & $47,2 b$ & $3,2 \mathrm{ab}$ & $15,6 \mathrm{~b}$ & $0,6 \mathrm{~b}$ \\
\hline Escarificado + DD & 1,4 & 0,47 & 0,31 & 0,17 & $16,6 \mathrm{a}$ & $61,3 \mathrm{a}$ & $3,9 \mathrm{a}$ & $21,6 \mathrm{a}$ & $1,0 \mathrm{a}$ \\
\hline Média & - & - & - & - & 13,9 & 45,7 & 3,0 & 14,4 & 0,6 \\
\hline CV (\%) & - & - & - & - & 6,4 & 4,7 & 18,7 & 14,7 & 19,7 \\
\hline
\end{tabular}

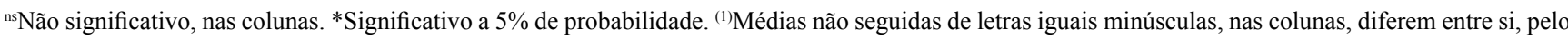

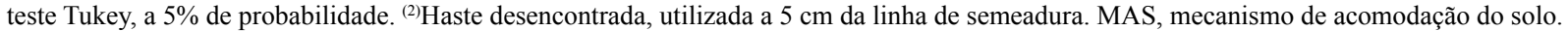


de nódulos no estádio V6, em ambas as safras (Tabelas 2 e 3 ).

Este resultado está associado ao menor efeito de redução da camada compactada do solo por esses sistemas, na linha de semeadura, em comparação aos demais, visto que a nodulação e a fixação biológica de $\mathrm{N}$ são afetadas pela presença de camada compactada do solo (Siczek \& Lipiec, 2011). Esses autores encontraram redução do número de nódulos por planta e redução da atividade da nitrogenase, em presença de camada compactada. Um dos efeitos indiretos da presença de camada compactada do solo sobre a fixação biológica de $\mathrm{N}$ ocorre pela redução do conteúdo de oxigênio no solo, o que inviabiliza a respiração das raízes (Lanza et al., 2013). Além disso, a atividade da nitrogenase é altamente dependente da disponibilidade de oxigênio (Justino \& Sodek, 2013). Assim, no presente experimento (Figura $1 \mathrm{~A}$ ), observa-se que o conteúdo de oxigênio no solo, na safra de 2013/2014, foi menor na maioria dos meses de desenvolvimento das plantas, no sistema com disco duplo, em comparação ao sistema com haste sulcadora. Nesse contexto, uma das possíveis explicações para a maior nodulação no sistema com escarificação do solo, seguido dos sistemas com haste sulcadora e microcamalhão, é que esses sistemas tenham proporcionado maior conteúdo de oxigênio

Tabela 2. Número de nódulos por planta (NNP), massa matéria seca de nódulos por planta (MSNP) e percentual de nódulos inviáveis (NI), nos estádios V6 e R3 de desenvolvimento da cultivar de soja 'BMX Tornado', em Santa Maria, RS, nas safras 2013/2014 e 2014/2015, e em Formigueiro, RS, na safra 2013/2014(1).

\begin{tabular}{|c|c|c|c|c|c|c|}
\hline \multirow[t]{2}{*}{ Sistema de plantio } & \multicolumn{2}{|c|}{ NNP } & \multicolumn{2}{|c|}{$\operatorname{MSNP}^{(2)}$ (mg por planta) } & \multicolumn{2}{|c|}{ Nódulos inviáveis ${ }^{(3)}(\%)$} \\
\hline & V6 & R3 & V6 & R3 & V6 & R3 \\
\hline & \multicolumn{6}{|c|}{ Experimento 1 em Santa Maria, safra 2013/2014 } \\
\hline Disco duplo (DD) & $35,5 \mathrm{~d}^{*}$ & $88,4^{\mathrm{ns}}$ & $100,6 \mathrm{c}$ & - & - & - \\
\hline Disco ondulado & $51,9 \mathrm{bc}$ & 96,5 & $150,0 \mathrm{~b}$ & - & - & - \\
\hline Haste & $53,6 \mathrm{bc}$ & 86,1 & $192,4 b$ & - & - & - \\
\hline Haste + MAS & $61,8 \mathrm{ab}$ & 86,8 & $179,3 b$ & - & - & - \\
\hline Microcamalhão & $42,3 \mathrm{~cd}$ & 102,9 & $169,2 b$ & - & - & - \\
\hline Escarificado + DD & $71,0 \mathrm{a}$ & 99,7 & $253,0 \mathrm{a}$ & - & - & - \\
\hline \multicolumn{7}{|l|}{ Irrigação } \\
\hline Com irrigação & $54,7^{\text {ns }}$ & $102,9^{\mathrm{ns}}$ & $193,3 \mathrm{a}$ & - & - & - \\
\hline Sem irrigação & 50,7 & 83,6 & $154,9 b$ & - & - & - \\
\hline Média & 52,7 & 93,2 & 174,1 & - & - & - \\
\hline \multirow[t]{2}{*}{ CV $(\%)$} & 17,8 & 21,1 & 24,8 & - & - & - \\
\hline & \multicolumn{6}{|c|}{ Experimento 2 em Formigueiro, safra 2013/2014 } \\
\hline Disco duplo (DD) & - & $13,1 b^{*}$ & - & $13,5 b$ & - & $4,2^{\text {ns }}$ \\
\hline Disco ondulado & - & $22,5 \mathrm{ab}$ & - & $38,1 \mathrm{~b}$ & - & 9,6 \\
\hline Haste & - & $29,8 \mathrm{a}$ & - & $68,3 \mathrm{ab}$ & - & 5,1 \\
\hline Haste + MAS & - & $29,2 \mathrm{a}$ & - & $132,6 \mathrm{a}$ & - & 6,5 \\
\hline Escarificado + DD & - & $28,1 \mathrm{a}$ & - & $56,3 \mathrm{ab}$ & - & 5,9 \\
\hline Média & - & 24,5 & - & 61,8 & - & 6,3 \\
\hline \multirow[t]{2}{*}{ CV $(\%)$} & - & 18,2 & - & 61,0 & - & 44,1 \\
\hline & \multicolumn{6}{|c|}{ Experimento 1 em Santa Maria, safra 2014/2015 } \\
\hline Disco duplo (DD) & $15,0 c^{*}$ & $54,5 \mathrm{c}$ & $116,6 \mathrm{~b}$ & $461,1 \mathrm{c}$ & $2,8 \mathrm{a}$ & $5,2^{\mathrm{ns}}$ \\
\hline Disco ondulado & $19,6 \mathrm{bc}$ & $52,4 \mathrm{c}$ & $122,2 b$ & $522,7 \mathrm{c}$ & $0,8 b$ & 3,6 \\
\hline Haste & $25,3 b$ & $79,9 \mathrm{bc}$ & $222,2 \mathrm{a}$ & $642,2 \mathrm{bc}$ & $0,4 \mathrm{~b}$ & 4,0 \\
\hline Haste desencontrada ${ }^{(4)}$ & $25,6 b$ & $74,8 \mathrm{bc}$ & $188,9 \mathrm{ab}$ & $667,7 \mathrm{bc}$ & $0,3 b$ & 4,3 \\
\hline Microcamalhão & $22,0 \mathrm{~b}$ & $88,2 b$ & $175,0 \mathrm{ab}$ & $760,0 \mathrm{ab}$ & $1,0 \mathrm{ab}$ & 2,3 \\
\hline Escarificado + DD & $37,7 \mathrm{a}$ & $126,4 \mathrm{a}$ & $211,1 \mathrm{a}$ & $946,7 \mathrm{a}$ & $0,2 \mathrm{~b}$ & 4,1 \\
\hline Média & 24,2 & 79,4 & 172,7 & 666,7 & 0,9 & 3,9 \\
\hline CV (\%) & 11,0 & 15,2 & 19,2 & 14,3 & 88,9 & 45,2 \\
\hline
\end{tabular}

${ }^{(1)}$ Médias não seguidas de letras iguais minúsculas, nas colunas, diferem entre si, pelo teste Tukey, a 5\% de probabilidade. (2)Houve interação entre os fatores para MSNP, em R3, e NI, em V6 e R3, na safra 2013/2014 para o experimento 1. (3)Não se realizou a avaliação no estádio V6. ${ }^{(4)}$ Haste desencontrada,

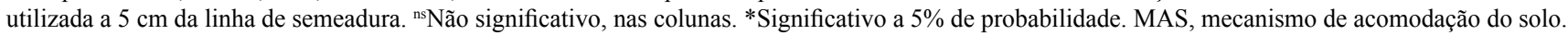


no solo na linha de semeadura, em consequência do aumento da macroporosidade do solo, que auxilia a drenagem e a aeração do solo.

Além dos efeitos benéficos pelo uso dos sistemas com haste (escarificação do solo, semeadura com haste sulcadora e semeadura em microcamalhão com haste sulcadora) quanto à redução da camada compactada na linha de semeadura, o que melhorou a qualidade física do solo, o crescimento e nodulação das plantas, observou-se que a irrigação também é uma importante prática de manejo em soja cultivada em área com camada compactada. A realização da irrigação de $55 \mathrm{~mm}$ proporcionou maior estatura e massa de matéria seca da parte aérea. Ruviaro et al. (2011), também encontraram resposta significativa da irrigação, em comparação à testemunha sem irrigação, e encontraram correlação de $93 \%$ entre o volume de água aplicado e a estatura das plantas. De acordo com Ferrari et al. (2015), o estresse causado por deficit de água leva à ocorrência de plantas de soja pouco desenvolvidas, com pequena estatura e área foliar reduzida, pois uma das alterações provocadas pelo estresse hídrico é a redução do potencial hídrico foliar, que causa o fechamento estomático e, consequentemente, a diminuição das trocas gasosas e a inibição de vários processos bioquímicos e fisiológicos, como a fotossíntese, respiração, absorção de íons, metabolismo dos nutrientes, entre outros. Além disso, a irrigação incrementou a massa de matéria seca de nódulos (Tabela 2), pois a nodulação é influenciada pelo conteúdo de água no solo (Siczek \& Lipiec, 2011), e a fixação biológica de $\mathrm{N}$ é um processo metabólico muito sensível ao deficit de água em plantas de soja (Gil-Quintana et al., 2013; King et al., 2014).

A redução da camada compactada no solo na linha de semeadura, pelos sistemas com haste, impactou positivamente o rendimento de grãos de soja em ambas as safras. Na safra de 2013/2014 (Tabela 3), o sistema com escarificação do solo proporcionou maior rendimento do que o sistema com o disco duplo, o qual, em números absolutos, foi o sistema que apresentou o menor rendimento entre todos os testados. A escarificação do solo incrementou a produtividade em $10 \%$. Na safra de $2014 / 2015$, os resultados foram semelhantes aos da safra 2013/2014, em que o maior rendimento foi observado no sistema com escarificação do solo, seguido dos sistemas de semeadura com haste sulcadora, haste sulcadora desencontrada a $5 \mathrm{~cm}$ da linha de semeadura e microcamalhão, e os menores rendimentos de grãos ocorreram nos sistemas com disco ondulado e duplo. O sistema com escarificação do solo, seguido da semeadura com haste e haste desencontrada a $5 \mathrm{~cm}$ da linha de semeadura, proporcionaram rendimento 26,15 e $12 \%$ superior ao do sistema com disco duplo.

Tabela 3. Massa de matéria seca de nódulos por planta (MSN), no estádio R3, percentual de nódulos inviáveis (NI), nos estádios V6 e R3 de desenvolvimento das plantas, e rendimento de grãos em consequência dos sistemas de corte da semadora e irrigação em Santa Maria, RS, safras 2013/2014 e 2014/2015, e em Formigueiro, RS, safra 2013/2014(1).

\begin{tabular}{|c|c|c|c|c|c|c|c|c|c|}
\hline \multirow{2}{*}{$\begin{array}{l}\text { Sistema de } \\
\text { plantio }\end{array}$} & \multicolumn{2}{|c|}{ MSN (mg por planta) } & \multicolumn{4}{|c|}{ Nódulos inviáveis (\%) } & \multicolumn{3}{|c|}{ Rendimento de grãos $\left(\mathrm{kg} \mathrm{ha}^{-1}\right)$} \\
\hline & CI no R3 & SI no R3 & CI no V6 & SI no V6 & CI no R3 & SI no R3 & Santa Maria & Formigueiro & Santa Maria \\
\hline & \multicolumn{6}{|c|}{ Experimento 1 em Santa Maria, safra 2013/2014 } & $2013 / 2014$ & $2013 / 2014$ & $2014 / 2015$ \\
\hline Disco duplo (DD) & $352,2^{\mathrm{NS}} \mathrm{c}^{*}$ & $289,0 \mathrm{ab}$ & $3,4 \mathrm{~B}^{\mathrm{ns}}$ & 11,9Aa & $6,1^{\mathrm{NSns}}$ & $7,6^{\mathrm{ns}}$ & $4.082 \mathrm{~b}$ & $2.642 \mathrm{c}$ & $3.759 \mathrm{~d}$ \\
\hline Disco ondulado & $763,6 \mathrm{Aa}$ & $237,2 \mathrm{Bb}$ & $1,2 \mathrm{~B}$ & $3,1 \mathrm{Ab}$ & $4,6^{\mathrm{NS}}$ & 3,8 & $4.273 \mathrm{ab}$ & $2.867 \mathrm{abc}$ & $3.829 \mathrm{~cd}$ \\
\hline Haste & $591,1 \mathrm{Aab}$ & $438,3 \mathrm{Ba}$ & $1,7^{\mathrm{NS}}$ & $2,8 b$ & $5,4^{\mathrm{NS}}$ & 6,7 & $4.405 \mathrm{ab}$ & $2.970 \mathrm{a}$ & $4.327 \mathrm{~b}$ \\
\hline Haste + MAS & $591,1 \mathrm{Aab}$ & $296,6 \mathrm{Bab}$ & $1,2^{\mathrm{NS}}$ & $0,9 \mathrm{~b}$ & $2,6 \mathrm{~B}$ & $7,7 \mathrm{~A}$ & $4.107 \mathrm{~b}$ & $2.917 \mathrm{ab}$ & - \\
\hline Haste desencontrada ${ }^{(2)}$ & - & - & - & - & - & - & - & - & $4.222 b$ \\
\hline Microcamalhão & $526,7^{\mathrm{NS}} \mathrm{bc}$ & $421,1 \mathrm{ab}$ & $2,0^{\mathrm{NS}}$ & $2,1 b$ & $6,0^{\mathrm{NS}}$ & 4,9 & $4.345 \mathrm{ab}$ & - & $4.013 \mathrm{c}$ \\
\hline Escarificado + DD & 570Aab & $306,6 \mathrm{Bab}$ & $2,8^{\mathrm{NS}}$ & $2,7 \mathrm{~b}$ & $4,5^{\mathrm{NS}}$ & 4,2 & $4.484 \mathrm{a}$ & $2.698 \mathrm{bc}$ & $4.749 \mathrm{a}$ \\
\hline \multicolumn{10}{|l|}{ Irrigação } \\
\hline Com irrigação & - & - & - & - & - & - & $4.444 \mathrm{a}$ & - & $4.311 \mathrm{a}$ \\
\hline Sem irrigação & - & - & - & - & - & - & $4.121 b$ & - & $3.988 b$ \\
\hline Média & 565,8 & 331,5 & 2,1 & 3,9 & 4,9 & 5,8 & 4.283 & 2.819 & 4.150 \\
\hline CV (\%) & \multicolumn{2}{|c|}{19,7} & \multicolumn{2}{|c|}{35,3} & \multicolumn{2}{|c|}{34,4} & 7,4 & 4,4 & 3,14 \\
\hline
\end{tabular}

${ }^{(1)}$ Médias não seguidas de letras iguais, maiúsculas nas linhas e minúsculas nas colunas, diferem entre si pelo teste Tukey, a $5 \%$ de probabilidade. ${ }^{(2)}$ Haste

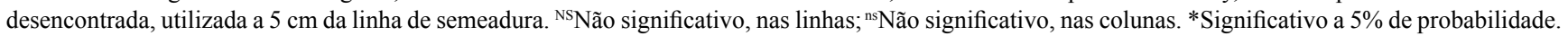
MAS, mecanismo de acomodação do solo; CI, com irrigação; SI, sem irrigação. 
A irrigação de $55 \mathrm{~mm}$, realizada em $\mathrm{V} 4$, resultou em aumento de $10 \%$ no rendimento de grãos, na safra de $2013 / 2014$, e $8 \%$ na safra de 2014/2015 quando foram aplicadas duas irrigações, de $41 \mathrm{~mm}$ e de $46 \mathrm{~mm}$, nos estádio R3 e R5, respectivamente. A água é fundamental para que a planta expresse seu potencial de resposta a toda e qualquer tecnologia empregada, pois, segundo Ruviaro et al. (2011), o uso da irrigação está diretamente relacionado à expressão do potencial da cultura. Essa limitação ocorre porque a água está envolvida na maioria dos processos bioquímicos e
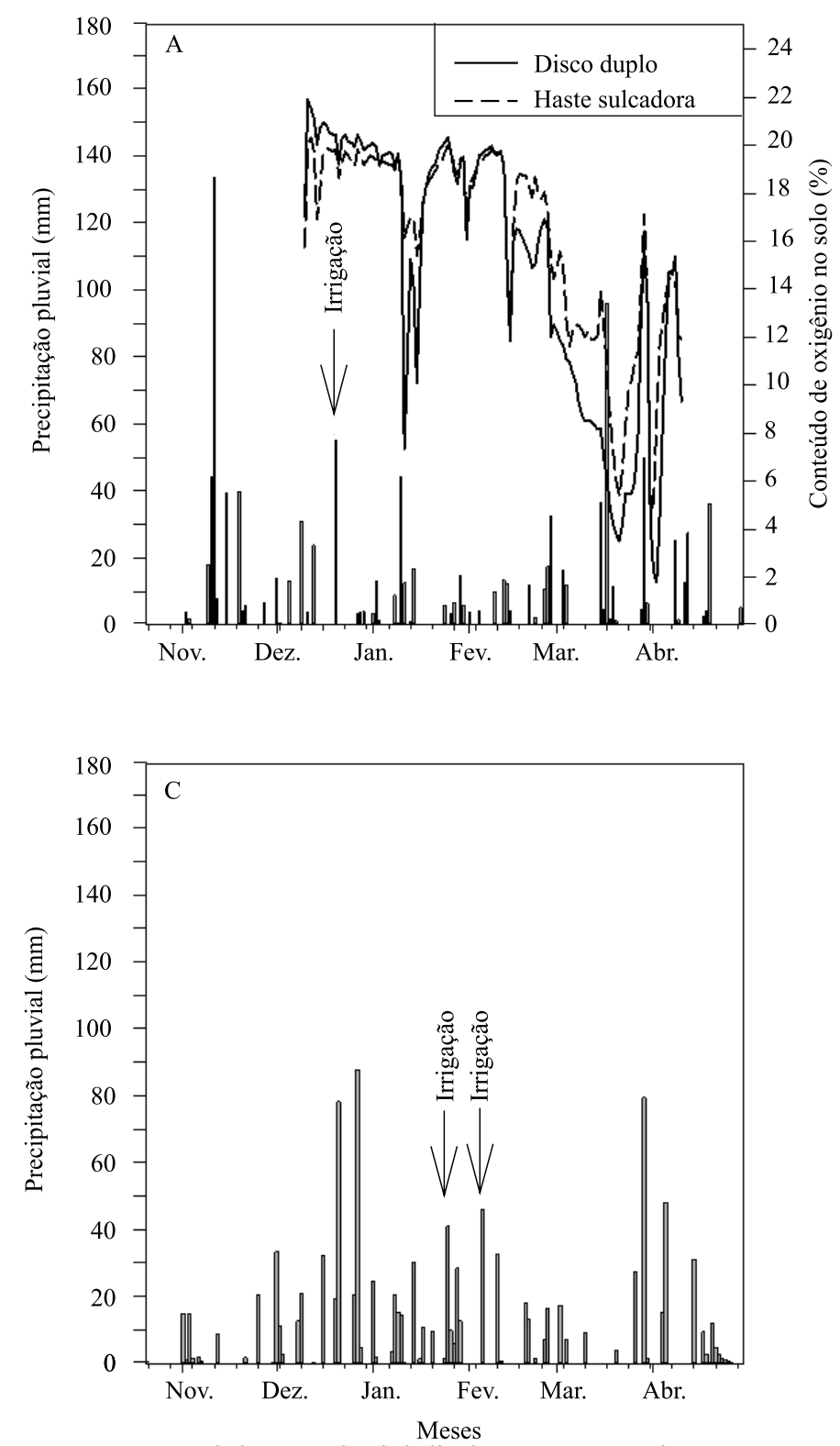

fisiológicos da planta (King et al., 2014; Du et al., 2015; Ferrari et al., 2015). Além disso, o aumento do rendimento de grãos, em consequência da irrigação, pode estar relacionado à maior nodulação das plantas, como foi verificado no presente estudo, pois a nodulação é um fator determinante no rendimento de grãos e está correlacionada a $40 \%$ do rendimento (Brandelero et al., 2009).

No experimento 2, a área em que foi realizado este estudo também apresentou uma camada compactada próxima à superfície do solo, caracterizada entre $5-5 \mathrm{~cm}$,
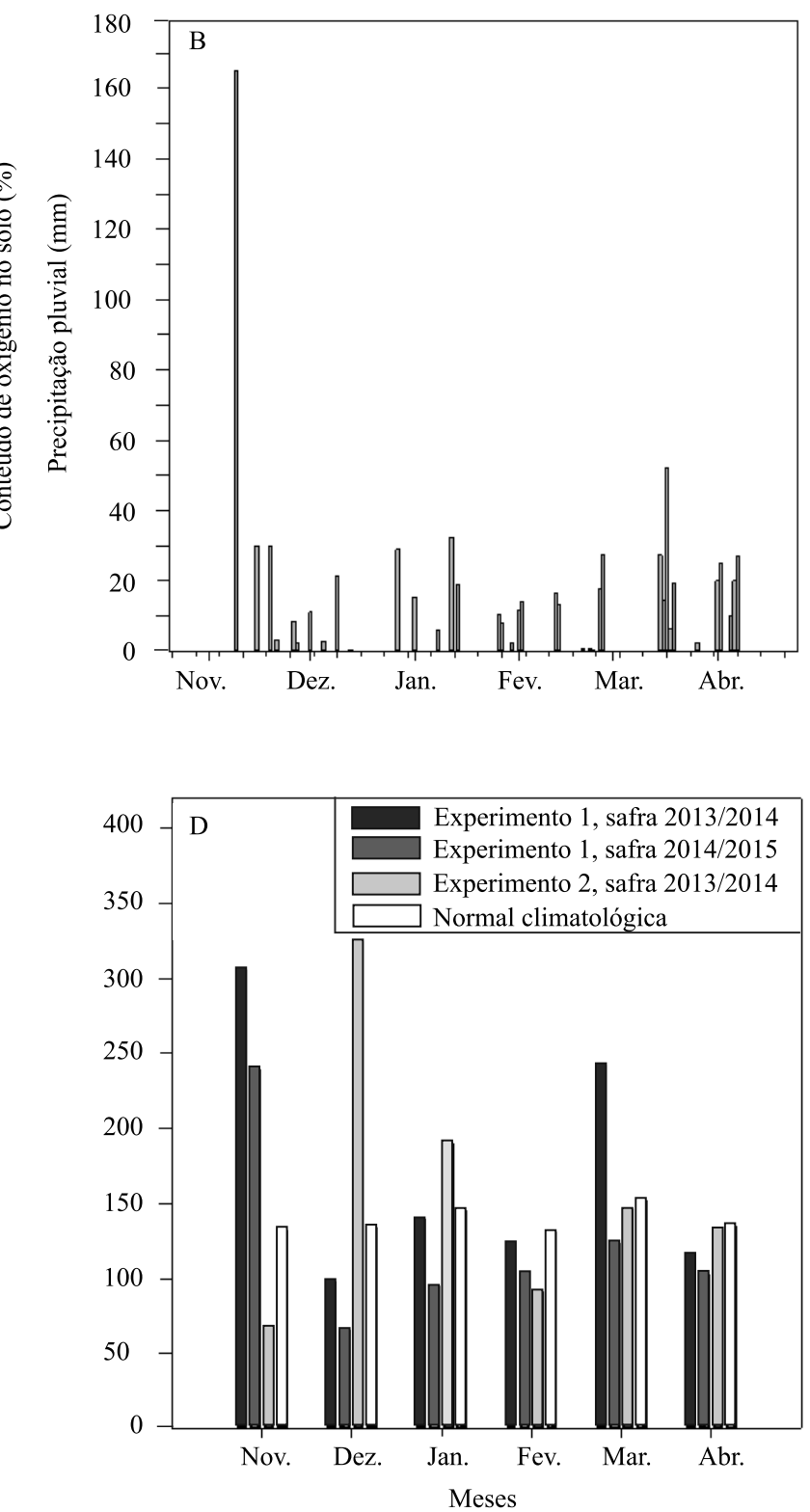

Figura 1. Precipitação pluvial diária para o experimento 1 em Santa Maria, RS, nas safras 2013/2014 (A) e 2014/2015 (C), para experimento 2 em Formigueiro, RS, na safra 2013/2014 (B), precipitação pluvial mensal e normal climatológica para Santa Maria (D) e conteúdo de oxigênio no solo (A). 
com valores de resistência do solo à penetração de até 3,0 MPa. Assim como observado nas duas safras de estudo no experimento 1 , no experimento 2 também se observou efeito positivo dos sistemas com escarificação do solo e haste sulcadora sobre a redução da camada compactada na linha de semeadura. De acordo com os resultados, esses sistemas reduziram a densidade do solo e aumentaram a porosidade total e a macroporosidade média na camada de $0-20 \mathrm{~cm}$ (Tabela 1). Em razão disso, esses sistemas impactaram positivamente o crescimento, a nodulação e o rendimento de grãos.

No sistema com escarificação do solo, houve maior estatura de plantas em R3 e massa de matéria seca da parte aérea e índice de área foliar em V6 (Tabela 1). Além disso, nesse sistema e no sistema com haste sulcadora, as plantas apresentaram maior número e massa de matéria seca de nódulos. Diferentemente do experimento 1 , no experimento 2 não se observou efeito da inviabilidade de nódulos. Isso pode ser atribuído às condições locais de solo de cada experimento, principalmente quanto ao relevo da área que, no experimento 1 , é plano, e no experimento 2 é suavemente ondulado.

Para o rendimento de grãos, o uso da haste sulcadora na semeadora incrementou em $12 \%$ o rendimento em relação ao disco duplo (Tabela 3). Assim como observado no experimento 1 , o menor rendimento de grãos ocorreu no sistema com disco duplo, como consequência de seu menor efeito de rompimento da camada compactada do solo, o que afetou o crescimento e a nodulação das plantas, que interfere na disponibilidade de $\mathrm{N}$ às plantas (Siczek \& Lipiec, 2011).

No experimento 2, o sistema com escarificação do solo apresentou menor rendimento de grãos em comparação ao uso da haste sulcadora. A hipótese para isto é que a escarificação do solo foi realizada no mesmo dia da semeadura, que foi seguida de duas gradagens para a uniformização da área, fato que, somado a uma precipitação de aproximadamente $200 \mathrm{~mm}$, durante um período de três dias após a semeadura, pode ter causado maior desestruturação do solo do que a semeadura com haste sulcadora.

No experimento 2 em Formigueiro, o rendimento de grãos foi menor do que no experimento $1 \mathrm{em}$ Santa Maria. Isto pode ser atribuído à menor nodulação das plantas e também à menor precipitação pluvial para alguns meses, em comparação a Santa Maria (Figura 1
D), visto que a nodulação (Brandelero et al., 2009) e a disponibilidade de água estão diretamente relacionadas ao rendimento de grãos de soja (Ruviaro et al., 2011).

De acordo com os resultados obtidos nos dois experimentos e safras agrícolas, observa-se que há resposta diferenciada dos sistemas de implantação quantoà redução da camada compactada eao rendimento de grãos de soja. Os sistemas com escarificação do solo, haste sulcadora e microcamalhão com haste sulcadora reduzem a densidade do solo, promovem o aumento da porosidade total e macroporosidade e incrementam o rendimento de grãos de soja em área com camada compactada. Na comparação com os sistemas com haste, verifica-se que o uso apenas dos mecanismos com disco duplo e disco ondulado de forma isolada não é eficiente na redução da camada compactada, pois apresentam o menor rendimento de grãos.

Assim, em áreas que apresentam camada compactada próxima à superfície do solo, principalmente nas áreas em rotação com a cultura do arroz irrigado, recomendase o uso de sistemas com haste, seja escarificação do solo, ou apenas uso da haste sulcadora na semeadora isolada ou, ainda, o sistema em microcamalhão, para que se tenha maior rendimento de grãos de soja. A irrigação suplementar em épocas de deficit hídrico, quando a umidade do solo se encontra abaixo de $60 \%$ da capacidade de campo, também é uma prática recomendada para minimizar os efeitos da camada compactada e do deficit hídrico, para promover aumento do rendimento de grãos da cultura da soja.

\section{Conclusões}

1. O uso dos sistemas com escarificação do solo e haste sulcadora, na semeadura, proporcionam maior rendimento de grãos de soja, em áreas que apresentam camada compactada próxima à superfície do solo.

2. A irrigação suplementar por faixas, realizada em condições de umidade do solo abaixo de $60 \%$ da capacidade de campo, resulta em acréscimo no rendimento de grãos de soja.

\section{Agradecimentos}

À Coordenação de Aperfeiçoamento de Pessoal de Nível Superior (Capes), ao Conselho Nacional de Desenvolvimento Científico e Tecnológico (CNPq), e à Fundação de Apoio à Pesquisa do Estado do Rio Grande do Sul (Fapergs), por concessão de bolsas.

Pesq. agropec. bras., Brasília, v.50, n.12, p.1139-1149, dez. 2015 DOI: $10.1590 / \mathrm{S} 0100-204 X 2015001200003$ 


\section{Referências}

ABREU, S.L.; REICHERT, J.M.; REINERT, D.J. Escarificação mecânica e biológica para a redução da compactação em argissolo franco-arenoso sob plantio direto. Revista Brasileira de Ciência do Solo, v.28, p.519-531, 2004. DOI: 10.1590/ S0100-06832004000300013.

BAMBERG, A.L.; PAULETTO, E.A.; GOMES, A. da S.; TIMM, L.C.; PINTO, L.F.S.; LIMA, A.C.R. de; SILVA, T.R. da. Densidade de um planossolo sob sistemas de cultivo avaliada por meio da tomografia computadorizada de raios gama. Revista Brasileira de Ciência do Solo, v.33, p.1079-1086, 2009. DOI: 10.1590/S0100-06832009000500001.

BRANDELERO, E.M.; PEIXOTO, C.P.; RALISCH, R. Nodulação de cultivares de soja e seus efeitos no rendimento de grãos. Semina: Ciências Agrárias, v.30, p.581-588, 2009. DOI: 10.5433/1679-0359.2009v30n3p581.

COSTAMILAN, L.M.; CARRÃO-PANZINI, M.C.; STRIEDER, M.L.; BERTAGNOLLI, P.F. (Org.). Indicações técnicas para a cultura da soja no Rio Grande do Sul e em Santa Catarina, safras 2012/2013 e 2013/2014. Passo Fundo: Embrapa Trigo, 2012. 142p. (Embrapa Trigo. Documentos, 107).

DONAGEMA, G.K.; CAMPOS, D.V.B. de; CALDERANO, S.B.; TEIXEIRA, W.G.; VIANA, J.H.M. (Org.). Manual de métodos de análise de solo. 2.ed. Rio de Janeiro: Embrapa Solos, 2011. 230p. (Embrapa Solos. Documentos, 132).

DRESCHER, M.S.; ELTZ, F.L.F.; DENARDIN, J.E.; FAGANELLO, A. Persistência do efeito de intervenções mecânicas para a descompactação de solos sob plantio direto. Revista Brasileira de Ciência do Solo, v.35, p.1713-1722, 2011. DOI: $10.1590 / \mathrm{S} 0100-06832011000500026$.

DU, T.S.; KANG, S.Z.; ZHANG, J.H.; DAVIES, W.J. Deficit irrigation and sustainable water-resource strategies in agriculture for China's food security. Journal of Experimental Botany, v.66, p.2253-2269, 2015. DOI: 10.1093/jxb/erv034.

FEHR, W.R.; CAVINESS, C.E. Stages of soybean development. Ames: Iowa State University of Science and Technology, 1977. 11p. (Special report, 80).

FERNANDES, E.J.; TURCO, J.E.P. Evapotranspiração de referência para manejo da irrigação em cultura de soja. Irriga, v.8, p.132-141, 2003.

FERRARI, E.; PAZ, A. da; SILVA, A.C. da. Déficit hídrico no metabolismo da soja em semeaduras antecipadas no Mato Grosso. Nativa, v.3, p.67-77, 2015. DOI: 10.14583/2318-7670.v03n01a12.

GIL-QUINTANA, E.; LARRAINZAR, E.; SEMINARIO, A.; DÍAZ-LEAL, J.L.; ALAMILLO, J.M.; PINEDA, M.; ARRESE-IGOR, C.; WIENKOOP, S.; GONZÁLEZ, E.M. Local inhibition of nitrogen fixation and nodule metabolism in drought-stressed soybean. Journal of Experimental Botany, v.64, p.2171-2182, 2013. DOI: 10.1093/jxb/ert074.

JUSTINO, G.C.; SODEK, L. Recovery of nitrogen fixation after short-term flooding of the nodulated root system of soybean.
Journal of Plant Physiology, v.170, p.235-241, 2013. DOI: 10.1016/j.jplph.2012.10.006.

KING, C.A.; PURCELL, L.C.; BOLTON, A.; SPECHT, J.E. A possible relationship between shoot $\mathrm{N}$ concentration and the sensitivity of $\mathrm{N}_{2}$ fixation to drought in soybean. Crop Science, v.54, p.746-756, 2014. DOI: 10.2135/cropsci2013.04.0271.

KIRNAK, H.; DOGAN, E.; ÇOPUR, O.; GOKALP, Z. Irrigation and yield parameters of soybean as effected by irrigation management, soil compaction and nitrogen fertilization. Journal of Agricultural Sciences, v.19, p.297-309, 2013.

LANZA, L.N.M.; ROSSI, S.C.; SODEK, L. Adubação nitrogenada beneficia soja alagada. Bragantia, v.72, p.2-9, 2013. DOI: 10.1590/S0006-87052013005000011.

MISSIO, E.L.; RUBIN, S. de A.L.; GABE, N.L.; OZELAME, J.G. Desempenho de genótipos de soja em solo hidromórfico de várzea. Pesquisa Agropecuária Gaúcha, v.16, p.23-29, 2010.

NUNES, M.R.; DENARDIN, J.E.; FAGANELLO, A.; PAULETTO, E.A.; PINTO, L.F.S. Efeito de semeadora com haste sulcadora para ação profunda em solo manejado com plantio direto. Revista Brasileira de Ciência do Solo, v.38, p.627-638, 2014. DOI: 10.1590/S0100-06832014000200027.

RADIN, B.; BERGAMASCHI, H.; REISSER JUNIOR, C.; BARNI, N.A.; MATZENAUER, R.; DIDONÉ, I.A. Eficiência de uso da radiação fotossinteticamente ativa pela cultura do tomateiro em diferentes ambientes. Pesquisa Agropecuária Brasileira, v.38, p.1017-1023, 2003. DOI: 10.1590/ S0100-204X2003000900001.

RUVIARO, C.; DORNELES, J.G.L.; SILVA, A.M.; BEN, C.A.V. Comportamento da soja submetida a diferentes regimes hídricos e viabilidade da irrigação suplementar na região do Vale do Jaguari-RS. Perspectiva, v.35, p.79-90, 2011.

SANTOS, H.G. dos; JACOMINE, P.K.T.; ANJOS, L.H.C. dos; OLIVEIRA, V.A. de; LUMBRERAS, J.F.; COELHO, M.R.; ALMEIDA, J.A. de; CUNHA, T.J.F.; OLIVEIRA, J.B. de. Sistema brasileiro de classificação de solos. 3.ed. Brasília: Embrapa, 2013. 353p.

SICZEK, A.; LIPIEC, J. Soybean nodulation and nitrogen fixation in response to soil compaction and surface straw mulching. Soil and Tillage Research, v.114, p.50-56, 2011. DOI: 10.1016/j.still.2011.04.001.

THOMAS, A.L.; PIRES, J.L.F.; MENEZES, V.G. Rendimento de grãos de cultivares de soja em solo de várzea. Pesquisa Agropecuária Gaúcha, v.6, p.107-112, 2000.

VALICHESKI, R.R.; GROSSKLAUS, F.; STURMER, S.L.K.; TRAMONTIN, A.L.; BAADE, E.S.A.S. Desenvolvimento de plantas de cobertura e produtividade da soja conforme atributos físicos em solo compactado. Revista Brasileira de Engenharia Agrícola e Ambiental, v.16, p.969-977, 2012. DOI: 10.1590/ S1415-43662012000900007.

VERNETTI JUNIOR, F. de J.; GOMES, A. da S.; SCHUCH, L.O.B. Sucessão de culturas em solos de várzea implantadas nos sistemas plantio direto e convencional. Revista Brasileira de Agrociência, v.15, p.37-42, 2009. 
VIEIRA NETO, S.A.; PIRES, F.R.; MENEZES, C.C.E. de; MENEZES, J.F.S.; SILVA, A.G. da; SILVA, G.P.; ASSIS, R.L. de. Formas de aplicação de inoculante e seus efeitos sobre a nodulação da soja. Revista Brasileira de Ciência do Solo, v.32, p.861-870, 2008. DOI: $10.1590 /$ S0100-06832008000200040.
ZHANG, T.; LIN, X.; SASSENRATH, G.F. Current irrigation practices in the central United States reduce drought and extreme heat impacts for maize and soybean, but not for wheat. Science of the Total Environment, v.58, p.331-342, 2015. DOI: 10.1016/j. scitotenv.2014.12.004.

Recebido em 29 de maio de 2015 e aprovado em 30 de outubro de 2015 